\title{
Effects of the circadian rhythm on milk composition in dairy cows: Does day milk differ from night milk?
}

\author{
Z. W. Teng, ${ }^{1} \odot$ G. Q. Yang, ${ }^{2} \odot$ L. F. Wang, ${ }^{1 *} \odot$ T. Fu, ${ }^{1}$ H. X. Lian, ${ }^{1}$ Y. Sun, ${ }^{1} \odot$ L. Q. Han, ${ }^{1}$ L. Y. Zhang, ${ }^{1}$ \\ and T. Y. Gao ${ }^{1 *}$ (1) \\ ${ }^{1}$ College of Animal Science and Technology, Henan Agricultural University, Zhengzhou, Henan 450046, People's Republic of China \\ ${ }^{2}$ Modern Experimental Technique and Management Centre, Henan Agricultural University, Zhengzhou, Henan 450002, \\ People's Republic of China
}

\begin{abstract}
Metabolism in most organisms can show variations between the day and night. These variations may also affect the composition of products derived from livestock. The aim of the present study was to investigate the difference in composition between the day milk and night milk of dairy cows. Ten multiparous Holstein cows $($ milk yield $=25.2 \pm 5.00 \mathrm{~kg} / \mathrm{d})$ were randomly selected during mid lactation. Milk samples were collected at $0500 \mathrm{~h}$ ("night milk") and $1500 \mathrm{~h}$ ("day milk") and analyzed to determine their composition. Mid-infrared spectroscopy was used to analyze macronutrient content of milk. Metabolomics and lipidomics were used to detect and analyze small molecules and fatty acids, respectively. An automatic biochemical analyzer and ELISA kits were used to determine biochemical indicators, as well as antioxidant and immune parameters in the milk. Though milk fat, protein, lactose, and total milk solids were not different between day milk and night milk, small molecules, metabolites and lipids, and hormones and cytokines differed between day milk and night milk. Regarding biochemical and immune-related indicators, the concentrations of malondialdehyde, HSP70, and HSP90 in night milk were lower than that in day milk. However, interferon- $\gamma$ levels were higher in night milk. Additionally, night milk was naturally rich in melatonin. Lipidomics analyses showed that the levels of some lipids in night milk were higher than those in day milk. Metabolomics analyses identified 36 different metabolites between day milk and night milk. Higher concentrations of N-acetyl-D-glucosamine, cisaconitate, and D-sorbitol were observed in day milk. However, the other 33 metabolites analyzed, including carbohydrates, lipids, AA, and aromatic compounds,
\end{abstract}

\footnotetext{
Received September 22, 2020.

Accepted March 4, 2021.

*Corresponding authors: wanglf1968@126.com and dairycow@163 .com
}

showed lower concentrations in day milk than in night milk. The present findings show that the composition of night milk differs considerably from that of day milk. Notable changes in the circadian rhythm also altered milk composition. These results provide evidence to support the strategic use and classification of day milk and night milk.

Key words: dairy cow, day milk, night milk, circadian rhythm

\section{INTRODUCTION}

Physiological processes are affected by the circadian system (Asher and Sassone-Corsi, 2015; Ribas-Latre and Eckel-Mahan, 2016). Most vital activities, including timing of hormone secretion and metabolic activities, exhibit distinct periodic variations with the day-night cycle (Kumar Jha et al., 2015). Researchers have shown that phospholipids, AA, and urea-cycle metabolites in mouse plasma all exhibit circadian oscillations (Minami et al., 2009). Recent studies have demonstrated that 60 to $70 \%$ of all metabolites in human blood samples oscillated in a circadian pattern (Davies et al., 2014). In sheep, plasma glucose concentrations peak at dusk (Piccione et al., 2005), and free fatty acid levels are lower at night and rise during the early morning hours (Alila-Johansson et al., 2004).

A previous study reported that melatonin (MLT) levels in the milk and blood of dairy cows show a diurnal rhythm (Castro et al., 2011). Milk contains all the essential nutrients to nourish and promote the growth of young mammals (Willett and Ludwig, 2020). As the nutrients in milk are transported from the blood, variations in the blood also affect the composition of the milk. Melatonin is a key hormone that shows circadian variations, with high levels during the scotoperiod and low levels during the photoperiod (Castro et al., 2011). It was reported that the MLT concentration of night milk averaged $14.87 \mathrm{pg} / \mathrm{mL}$; however, it was $6.98 \mathrm{pg} /$ $\mathrm{mL}$ in the total daily milk (Romanini et al., 2019). In 
summer, the milk MLT concentration was lower than in the winter. These variables may relate to illuminance (Romanini et al., 2019). Moreover, night milk exhibits superior quality, as its SCC values are generally lower (Asher et al., 2015). Nevertheless, the differences of milk fat, protein, lactose, and minor lipid and carbohydrate compounds between day milk and night milk have been seldom reported.

Few studies profile the differences of metabolites or the specific species of lipids and carbohydrates between day milk and night milk. To gain a deeper understanding of these differences, milk composition was analyzed using advanced techniques, such as metabolomics and lipidomics, among others. The aim of the present study was to determine the differences of metabolites between day milk and night milk and provide a new theoretical basis for the selective use of milk.

\section{MATERIALS AND METHODS}

\section{Animals, Diets, and Experimental Design}

All animal experimental procedures were approved by Animal Care and Use Committee of Henan Agricultural University. The study was conducted in late August with a photoperiod of about $13 \mathrm{~h}$ of daylight (0600-1900 h) and $11 \mathrm{~h}$ of darkness. Ten multiparous Holstein (parity 2) cows of similar age, BW (470 \pm 50 $\mathrm{kg})$, and lactation stage $(150 \pm 20 \mathrm{~d})$ with an average milk yield of $25.2 \pm 5.0 \mathrm{~kg} / \mathrm{d}$ (mean $\pm \mathrm{SD}$ ) were selected. All cows were housed in a shaded open barn under natural lighting conditions. No artificial light was used in the barn. Cows were fed a TMR twice per day, and had free access to water and feed throughout the study. The TMR contained (DM basis) $25.0 \%$ corn silage, $20.0 \%$ alfalfa hay, $7.0 \%$ oat hay, $20.0 \%$ steamflaked corn, $3.0 \%$ cottonseed, $12.7 \%$ soybean meal, $2.1 \%$ beet pulp, $3.9 \%$ brewer's grain, $2.0 \%$ molasses, and $4.3 \%$ premix (Hefeng Feed Co. Ltd.).

\section{Sample Collection and Analysis}

Two aliquots $(50 \mathrm{~mL})$ of milk were collected from each of the 10 cows at $0500 \mathrm{~h}$ ("night milk") and 1500 h ("day milk") using milk sampling devices (Waikato Milking Systems NZ Ltd.), minimizing stress or disturbance to the animals. Sampling was repeated over 3 consecutive days, and then the day milk and night milk samples of each cow were mixed in equal proportion. These aliquots were further split into 5 cryovials (10 $\mathrm{mL}$ ) and stored at $4^{\circ} \mathrm{C}$ in an incubator. Milk composition, including the levels of fat, protein, lactose, and total solids, as well as the SCC were detected within 6 $\mathrm{h}$ of collection using a MilkoScan $\mathrm{FT}^{+}$analyzer (Foss Electric A/S). Samples allocated for metabolomics and lipidomics were immediately stored in a liquid nitrogen container to minimize any possible metabolite degradation, and then transferred to a cryogenic refrigerator and stored at $-80^{\circ} \mathrm{C}$ until further analysis.

For biochemical analysis, $10 \mathrm{~mL}$ of the milk samples were skimmed by centrifugation at $3,000 \times g$ for 15 min at $4^{\circ} \mathrm{C}$, and then centrifuged at $12,000 \times g$ for 30 min at $4^{\circ} \mathrm{C}$ using a high-speed freezing centrifuge (Avanti JXN-30, Beckman Coulter). The supernatant was decanted into a vial and stored at $-80^{\circ} \mathrm{C}$ until further analysis. Biochemical indices, such as superoxide dismutase, malondialdehyde (MDA), glutathione reductase, and glutathione peroxidase; as well as metabolism-related hormones, including MLT, growth hormone, triiodothyronine, insulin, glucagon, cortisol, and adrenaline; and immune factors, such as $\operatorname{IgA}, \operatorname{IgG}$, TNF- $\alpha$, IL-1 $\beta$, IL-6, IL-8, IFN- $\gamma$, CD4, and CD8 were measured spectrophotometrically using ELISA kits (Shanghai BlueGene Biotechnology Co., Ltd.) according to the manufacturer's instructions. The inter- and intra-assay coefficient of variations of these kits were $<12$ and $<10 \%$, respectively. These kits have a high analytical sensitivity and no obvious cross reactivity. Complete details and potential limitations of each kit is shown in Supplemental Table S1 (https://doi.org/10 .6084/m9.figshare.14350580.v1, Teng, 2021).

\section{Lipidomics}

Sample Preparation and Extraction. The lipidomics samples were thawed slowly at $4^{\circ} \mathrm{C}$ and mixed by vortexing. Milk samples $(100 \mu \mathrm{L})$ were added to $200 \mu \mathrm{L}$ of water and vortexed. Cold methanol $(200 \mu \mathrm{L})$ was then added to the composite milk samples and revortexed. The composite milk samples were then added to 800 $\mu \mathrm{L}$ of methyl tert butyl ether (MTBE) and thoroughly vortex mixed. All sample mixtures were placed in an ultrasound water bath at $4^{\circ} \mathrm{C}$ for $20 \mathrm{~min}$, and stored at $25^{\circ} \mathrm{C}$ for 30 min before being centrifuged at $14,000 \times g$ for $15 \mathrm{~min}$ at $10^{\circ} \mathrm{C}$. The supernatant was then decanted and freeze-dried in nitrogen, and reconstituted with 300 $\mu \mathrm{L}$ of $90 \%$ isopropanol-acetonitrile (1:1, vol/vol). The reconstituted solution was vortexed and centrifuged $\left(14,000 \times g\right.$, for $15 \mathrm{~min}$ at $\left.10^{\circ} \mathrm{C}\right)$. The resulting supernatant was used for LC-MS/MS analysis.

Liquid Chromatography Positive Ion Electrospray Ionization Tandem MS Analysis. Milk samples were separated using a Nexera LC-30A (Nexera LC-30A, Shimadzu) ultrahigh performance liquid chromatography (UHPLC) hydrophilic interaction chromatography column (ACQUITY UPLC 
BEH Amide $1.7 \mu \mathrm{m}, 2.1 \mathrm{~mm} \times 100 \mathrm{~mm}$ column). The temperature of the column was set at $45^{\circ} \mathrm{C}$ and the injection volume was $3 \mu \mathrm{L}$. The mobile phase consisted of phases A and B. Mobile phase A was constituted using ammonium acetonitrile formate aqueous solution (acetonitrile:water $=6: 4, \mathrm{vol} / \mathrm{vol}$ ) and mobile phase $\mathrm{B}$ was ammonium formate acetonitrile isopropanol solution (acetonitrile:isopropanol $=1: 9, \mathrm{vol} / \mathrm{vol}$ ). The mobile phase was delivered at a flow rate of $300 \mu \mathrm{L} / \mathrm{min}$ using the following gradient: 0 to $2 \mathrm{~min}, 30 \% \mathrm{~B} ; 2$ to 25 $\min , 30$ to $100 \% \mathrm{~B}$; and 25 to $35 \mathrm{~min}, 30 \% \mathrm{~B}$.

The samples were separated by UHPLC and analyzed on the Q Exactive Plus mass spectrometer (Thermo Fisher Scientific). The electrospray ionization (ESI) source conditions were as follows in the positive mode: heater temperature $=300^{\circ} \mathrm{C}$; sheath gas flow rate $=45$ arbitrary units ( $\mathbf{a r b})$; auxiliary gas flow rate $=15$ arb; sweep gas flow rate $=1 \mathrm{arb}$; spray voltage $=3.0 \mathrm{kV}$; capillary temperature $=350^{\circ} \mathrm{C}$; S-lens radio frequency level $=50 \%$; and first order mass spectrum $\left(\mathrm{MS}^{1}\right)$ scan ranges $=200$ to 1,800 . In the negative mode: heater temperature $=300^{\circ} \mathrm{C}$; sheath gas flow rate $=45$ arb; auxiliary gas flow rate $=15$ arb; sweep gas flow rate $=1 \mathrm{arb}$; spray voltage $=2.5 \mathrm{kV}$; capillary temperature $=350^{\circ} \mathrm{C} ; \mathrm{S}$-Lens radio frequency level $=60 \%$; and $\mathrm{MS}^{1}$ scan ranges $=250$ to 1,800 . The mass charge ratio of lipid molecules and lipid fragments was determined according to the following protocol: 10 fragments [second order mass spectrum $\left(\mathrm{MS}^{2}\right)$ scan, high-energy collisional dissociation) were collected after each full scan. The resolution of $\mathrm{MS}^{1}$ at $m / z 200$ was 70,000 , and that of $\mathrm{MS}^{2}$ was 17,500 .

\section{Metabolomics}

Sample Preparation and Extraction. The metabolomics samples were thawed at $4^{\circ} \mathrm{C}$ and then shaken and mixed evenly. A volume of $100 \mu \mathrm{L}$ of a milk sample was added to $400 \mu \mathrm{L}$ of cold methanol-acetonitrile (1:1, $\mathrm{vol} / \mathrm{vol}$ ), and the mixture was vortexed. All sample mixtures were stored at $-20^{\circ} \mathrm{C}$ for $60 \mathrm{~min}$, and then centrifuged at $14,000 \times g$ for $20 \mathrm{~min}$ at $4^{\circ} \mathrm{C}$. The supernatant was collected, vacuum dried, and reconstituted with $100 \mu \mathrm{L}$ of water-acetonitrile $(1: 1, \mathrm{vol} / \mathrm{vol})$. The reconstituted solution was vortexed and centrifuged at $14,000 \times g$ for 15 min at $4^{\circ} \mathrm{C}$. The supernatant was used for LC-MS/MS analysis.

The LC-ESI-MS/MS Analysis. Prepared samples were separated using an UHPLC hydrophobic interaction chromatography column (Agilent 1290 Infinity LC, ACQUITY UPLC BEH Amide $1.7 \mu \mathrm{m}, 2.1 \mathrm{~mm} \times 100$ $\mathrm{mm}$ column). The temperature of the column was $25^{\circ} \mathrm{C}$ and the injection volume was $2 \mu \mathrm{L}$. The mobile phase
A was constituted using $25 \mathrm{mM}$ ammonium acetate and $25 \mathrm{~m} M$ aqua ammonia in water, and mobile phase $\mathrm{B}$ was acetonitrile. The mobile phase $\mathrm{B}$ was delivered at a flow rate of $0.3 \mathrm{~mL} / \mathrm{min}$ using the following gradient: 0 to $1 \mathrm{~min}, 95 \% \mathrm{~B} ; 1$ to $14 \mathrm{~min}, 95$ to $65 \% \mathrm{~B} ; 14$ to 16 min, 65 to $45 \%$ B; 16 to $18 \mathrm{~min}, 40 \% \mathrm{~B} ; 18$ to $18.1 \mathrm{~min}$, 40 to $95 \% \mathrm{~B} ; 18.1$ to $23 \mathrm{~min}, 95 \% \mathrm{~B}$. To prevent the effects of fluctuations in instrument signal detection, a random sequence was used for continuous analysis of the samples. Processed sample stability was determined by repeated analysis of quality control milk samples. During the entire process of analysis, samples were placed in an automatic sampler at $4^{\circ} \mathrm{C}$.

Samples were separated by UHPLC and analyzed on a Triple TOF 5600 mass spectrometer (AB SCIEX). The ESI positive and negative modes were used, and multiple reaction monitoring parameters were as follows: ion source gas 1 (gas 1$)=60$ psi; ion source gas 2 (gas $2)=60 \mathrm{psi}$; curtain gas $=30 \mathrm{psi}$; source temperature $=$ $600^{\circ} \mathrm{C}$, ion spray voltage floating $= \pm 5,500 \mathrm{~V}$ (positive and negative modes); time-of-flight MS scan $\mathrm{m} / z$ range $=60$ to 1,000 Da; product ion scan $m / z$ range $=25$ to 1,000 Da; time-of-flight MS scan accumulation time $=0.20 \mathrm{~s} /$ spectra $;$ and product ion scan accumulation time $=0.05 \mathrm{~s} / \mathrm{spectra}$. Information-dependent acquisition was used for secondary mass spectrometry, and a high-sensitivity model was adopted. The declustering potential $= \pm 60 \mathrm{~V}$ (positive and negative modes); collision energy $=35 \pm 15 \mathrm{eV}$. The information-dependent acquisition parameters were set as follows: exclude isotopes within $4 \mathrm{Da}$; candidate ions to monitor per cycle $=6$.

\section{Statistical Analysis}

The raw MS data for the metabolomics were converted to mzXML files using ProteoWizard MS Convert and processed using XCMS (Umetrics) for feature detection, retention-time correction, and alignment. The metabolites were identified by accuracy mass $(<25$ ppm) and MS/MS data that were matched with our standards database. LipidSearch software version 4.1 (Thermo Scientific) was used for feature detection, retention-time correction, and alignment.

In the extracted ion features, only variables having more than $50 \%$ of the nonzero measurement values in at least 1 group were retained. The data were normalized by the total peak area. The SIMCA-P14.1 (Umetrics) was used for the pattern recognition multivariate statistical analysis. After Pareto scaling, principal component analysis, partial least squares discriminant analysis (PLS-DA) and orthogonal PLS-DA (OPLS-DA) were performed. Principal component analysis was used 
to visualize the data set, including the similarities and differences. The PLS-DA model was validated by 7 -fold permutation tests to assess its validity. The OPLS-DA was performed to maximize the covariance between the measured data and the response variable. To avoid over-fitting, model validity was evaluated by a permutation test (Spicer et al., 2017). Significantly different metabolites were metabolites with variable influence on projection (VIP) values from the OPLS-DA model greater than 1.0 and $P$ values less than 0.05 for 2 -tailed Student's $t$-tests of the raw data.

Differential metabolites were further identified using the Kyoto Encyclopedia of Genes and Genomes (KEGG; http://www.kegg.jp/) online database. The KEGG pathway enrichment of the differentially expressed metabolites was assessed using Fisher's Exact Test; $P<0.05$ was the significance threshold. The volcano map was created using $\mathrm{R}$ software (version 3.5.1, https://www.r-project.org/).

Milk composition data, biochemical parameters, hormone levels, and immune indices were analyzed using the SPSS version 18 software (IBM). Differences between means were determined by the Tukey test. Milk composition data, biochemical parameters, hormone levels, and immune indices were used as the test variables, and the night milk and day milk were used as grouping variables. Statistical significance was set at $P$ $<0.05 ; P<0.01$ was considered highly significant; 0.05 $\leq P<0.10$ was considered a tendency.

\section{RESULTS}

\section{Composition of Day Milk and Night Milk}

The composition of day milk and night milk is presented in Table 1. Milk fat, protein, lactose, and total milk solids were not different $(P>0.05)$.

\section{Antioxidants, Immune Parameters, and Hormone Concentrations in Milk}

Though the general composition remained stable, the specific composition and properties, such as antioxi-

Table 1. General composition of day milk and night milk $(\mathrm{n}=10)$

\begin{tabular}{lrrrr}
\hline Item & $\begin{array}{c}\text { Day- } \\
\text { milk }^{1}\end{array}$ & $\begin{array}{c}\text { Night- } \\
\text { milk }^{2}\end{array}$ & SEM & $P$-value \\
\hline Milk fat (\%) & 4.15 & 4.42 & 0.23 & 0.259 \\
Milk protein (\%) & 3.23 & 3.31 & 0.21 & 0.715 \\
Milk lactose (\%) & 4.86 & 4.90 & 0.11 & 0.769 \\
Total milk solids (\%) & 13.48 & 13.65 & 0.61 & 0.779 \\
SCC $\left(10^{5} / \mathrm{mL}\right)$ & 38.50 & 29.68 & 19.16 & 0.655 \\
\hline
\end{tabular}

${ }^{1}$ Day milk $=$ milk samples were collected at $1500 \mathrm{~h}$.

${ }^{2}$ Night milk $=$ milk samples were collected at $0500 \mathrm{~h}$.
Table 2. Antioxidant parameters of day milk and night milk $(\mathrm{n}=10)$

\begin{tabular}{lrrrc}
\hline Item $^{1}$ & $\begin{array}{c}\text { Day- } \\
\text { milk }^{2}\end{array}$ & $\begin{array}{c}\text { Night- } \\
\text { milk }^{3}\end{array}$ & SEM & $P$-value \\
\hline SOD $(\mu \mathrm{g} / \mathrm{mL})$ & 1.27 & 1.37 & 0.07 & 0.212 \\
GSH-Px $(\mathrm{ng} / \mathrm{mL})$ & 18.56 & 16.51 & 1.45 & 0.212 \\
GR $(\mathrm{ng} / \mathrm{mL})$ & 1.90 & 1.97 & 0.27 & 0.806 \\
MDA $(\mathrm{ng} / \mathrm{mL})$ & 6.01 & 5.24 & 0.33 & 0.044 \\
\hline
\end{tabular}

${ }^{1} \mathrm{SOD}=$ superoxide dismutase; GSH-Px = glutathione peroxidase; GR $=$ glutathione reductase; $\mathrm{MDA}=$ malondialdehyde.

${ }^{2}$ Day milk $=$ milk samples were collected at $1500 \mathrm{~h}$.

${ }^{3} \mathrm{Night}$ milk $=$ milk samples were collected at $0500 \mathrm{~h}$.

dant parameters (Table 2), immune indicators (Table 3 ), and relevant hormones (Table 4) showed a great difference between day milk and night milk. As shown in Table 2, the concentrations of MDA in day milk were higher than those of night milk $(P=0.044)$. Immune parameters of day milk and night milk are presented in Table 3. The levels of some immune indicators, such as IL-6, HSP70, and HSP90, were significantly reduced $(P<0.05)$ in night milk. However, the levels of IFN- $\gamma$ were significantly increased $(P=0.014)$ in night milk. Other immune indices showed no significant differences between day milk and night milk $(P>0.05)$. Table 4 lists the concentrations of hormones in day milk and night milk. Most of the related hormones in night milk showed no significant differences from those in day milk, with the exception of MLT $(P=0.002)$. The MLT levels in night milk $(P=0.002)$ were significantly higher than those in day milk.

\section{Lipidomics Findings}

Lipid composition based on lipidomics analysis is listed in Supplemental Figure S1 (https://doi.org/10 .6084/m9.figshare.14350580.v1, Teng, 2021) and Figure

Table 3. Immune parameters of day milk and night milk $(\mathrm{n}=10)$

\begin{tabular}{|c|c|c|c|c|}
\hline Item $^{1}$ & $\begin{array}{l}\text { Day- } \\
\text { milk }^{2}\end{array}$ & $\begin{array}{l}\text { Night- } \\
\text { milk }^{3}\end{array}$ & SEM & $P$-value \\
\hline $\operatorname{IgA}(\mathrm{mg} / \mathrm{mL})$ & 0.92 & 0.98 & 0.055 & 0.332 \\
\hline $\mathrm{IgG}(\mathrm{mg} / \mathrm{mL})$ & 3.67 & 3.72 & 0.334 & 0.876 \\
\hline TNF- $\alpha(p g / m L)$ & 85.72 & 88.61 & 5.31 & 0.599 \\
\hline $\mathrm{IL}-1 \beta(\mathrm{pg} / \mathrm{mL})$ & 78.60 & 73.93 & 8.87 & 0.611 \\
\hline IL-6 (pg/mL) & 191.31 & 141.46 & 21.52 & 0.059 \\
\hline IL-8 (pg/mL) & 64.79 & 68.56 & 4.44 & 0.416 \\
\hline $\operatorname{IFN}-\gamma(\mathrm{pg} / \mathrm{mL})$ & 55.54 & 70.40 & 5.01 & 0.014 \\
\hline HSP70 (ng/mL) & 5.50 & 4.19 & 0.36 & 0.005 \\
\hline HSP90 (ng/mL) & 3.83 & 3.42 & 0.147 & 0.022 \\
\hline CD4 (ng/mL) & 4.23 & 3.97 & 0.264 & 0.374 \\
\hline CD8 (ng/mL) & 2.39 & 1.99 & 0.320 & 0.236 \\
\hline CD4:CD8 & 1.86 & 2.00 & 0.173 & 0.431 \\
\hline
\end{tabular}

${ }^{1} \mathrm{TNF}=$ tumor necrosis factor; HSP $=$ heat shock protein; $\mathrm{CD}=$ clus ter of differentiation.

${ }^{2}$ Day milk $=$ milk samples were collected at $1500 \mathrm{~h}$.

${ }^{3} \mathrm{Night}$ milk $=$ milk samples were collected at $0500 \mathrm{~h}$. 
Table 4. Concentration of hormones in day milk and night milk (n $=10$ )

\begin{tabular}{lrrrc}
\hline Item & \multicolumn{1}{c}{$\begin{array}{c}\text { Day- } \\
\text { milk }^{2}\end{array}$} & $\begin{array}{c}\text { Night- } \\
\text { milk }^{3}\end{array}$ & SEM & $P$-value \\
\hline MLT (pg/mL) & 90.21 & 120.07 & 7.21 & 0.002 \\
CORT (ng/mL) & 113.72 & 102.69 & 7.99 & 0.198 \\
T3 (ng/mL) & 176.55 & 168.05 & 15.77 & 0.602 \\
GCN (ng/mL) & 2.68 & 2.56 & 0.252 & 0.653 \\
GH (ng/mL) & 4.85 & 4.76 & 0.808 & 0.915 \\
INS (ng/mL) & 0.81 & 0.80 & 0.087 & 0.910 \\
ADR (ng/mL) & 10.32 & 8.25 & 0.996 & 0.065 \\
\hline
\end{tabular}

${ }^{1} \mathrm{MLT}=$ melatonin $; \mathrm{CORT}=$ cortisol; $\mathrm{T} 3=$ triiodothyronine $; \mathrm{GCN}=$ glucagon; $\mathrm{GH}=$ growth hormone; $\mathrm{INS}=$ insulin; $\mathrm{ADR}=$ adrenaline.

${ }^{2}$ Day milk = milk samples were collected at $1500 \mathrm{~h}$.

${ }^{3} \mathrm{Night}$ milk $=$ milk samples were collected at $0500 \mathrm{~h}$.

1. A total of 21 lipid classes and 1,094 lipid species were detected in the milk samples, which were identified in the triglyceride (TG), phosphatidylcholine, phosphatidylethanolamine, phosphatidylserine, phosphatidylinositol, sphingomyelin, ceramide, O-acyl- $\omega-$ hydroxy fatty acid, and diacylglycerol categories. The OPLS-DA of the lipidomics results showed significantly separated clusters between the day milk and night milk groups in each score plot (Figure 2). Figure 2 illustrates the OPLS-DA results showing a clear separation and distinction between the day milk and night milk. The OPLS-DA models were not overfitted by permutation test. According to Figure 3, no significant differences were observed in 21 lipid classes between night milk and day milk. However, the relative abundances of most lipid classes in day milk were higher than those in night milk. Among the lipid species analyzed, 3 lipid $\left[\mathrm{TG}(16: 0 / 14: 0 / 18: 2)+\mathrm{NH}_{4}, \mathrm{TG}(19: 1 / 18: 1 / 18: 2)+\right.$ $\mathrm{NH}_{4}$, and $\left.\mathrm{TG}(18: 1 / 18: 1 / 22: 4)+\mathrm{NH}_{4}\right]$ metabolites of the TG category (fold change; $\mathbf{F C}>1.5$ and $P<0.05$ ) showed significant differences between day milk and night milk (Table 5).

\section{Metabolomics Results}

The OPLS-DA analysis of LC-MS metabolic profiles showed significantly separate clusters between the day milk and night milk groups in each OPLS-DA score plot (Figure 4). Figure 4 illustrates the OPLS-DA results, showing a clear separation and distinction between day milk and night milk. These findings indicate that the OPLS-DA model can be used to identify the differences between day milk and night milk. Figure 5 shows different metabolites according to FC $>1.5$ and $P<0.05$ in positive and negative mode between day milk and night milk. Metabolites with a VIP $>1$, and $P<0.05$ were selected as the metabolites showing significant differences (Table 6).

\section{Volcano Plot}

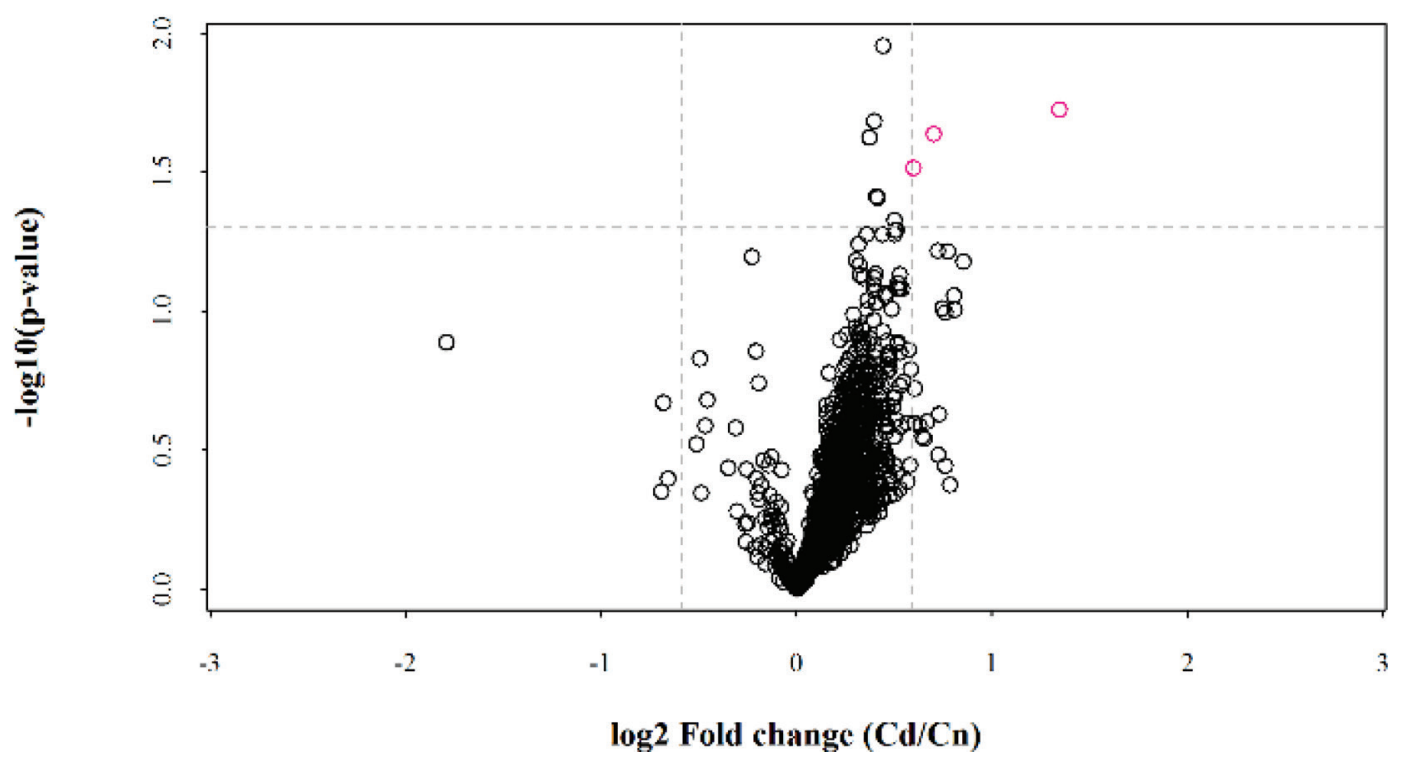

Figure 1. Volcano plot of lipidomics illustrating compounds differing between day milk and night milk $(\mathrm{n}=10)$. Red points indicate the significantly different lipids $(\mathrm{FC}>1.5$ and $P<0.05)$. FC $=$ fold change; mean value of peak area obtained from day milk group/mean value of peak area obtained from night milk group. $\mathrm{Cd}=$ day milk; $\mathrm{Cn}=$ night milk. 
Significantly Different Metabolites and Key Metabolic Pathways Showing Differences Between Day Milk and Night Milk

As shown in Table 6, a total of 36 significantly different metabolites (VIP $>1$ and $P<0.05$ ) were identified between day milk and night milk. The levels of N-acetyl-D-glucosamine, cis-aconitate, and D-sorbitol were higher in day milk than they were in night milk. The other 33 metabolites were lower in day milk that they were in night milk. These metabolites were associated with carbohydrates, lipids, AA, and aromatic metabolic products.

The KEGG pathway analysis (Figure 6) of the differential metabolites showed that the most enriched pathway was the mTOR signaling pathway, followed by the D-arginine and D-ornithine metabolic pathway, taurine and hypotaurine metabolic pathway, galactose metabolic pathway, and pyrimidine metabolic pathway.



B

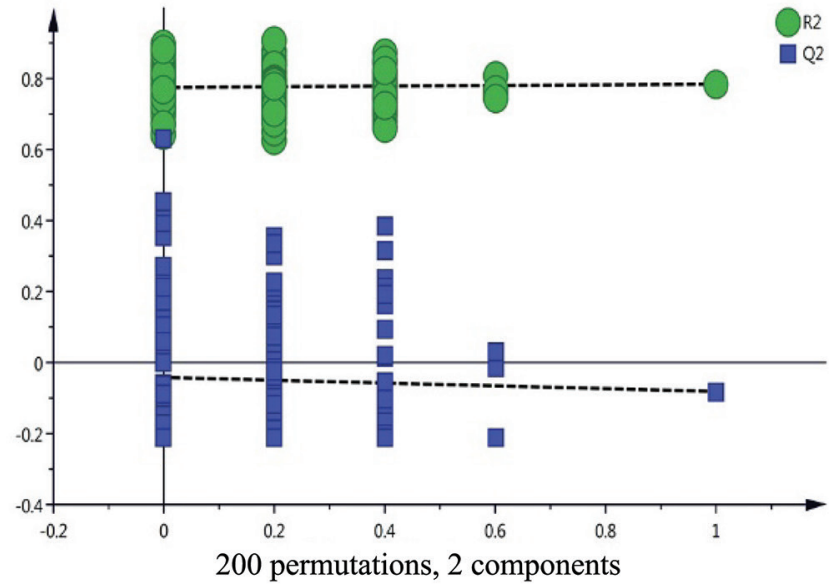

Figure 2. Orthogonal partial least squares discriminant analysis (OPLS-DA) score plots (A) and corresponding validation plots of partial least squares discriminant analysis (PLS-DA) (B) based on lipidomics analysis. Blue points represent day milk, and yellow points represent night milk. $\mathrm{Cd}=$ day milk; $\mathrm{Cn}=$ night milk.
The significant pathways were those associated with the ATP-binding cassette transporters, galactose metabolism, pyrimidine metabolism, taurine and hypotaurine metabolism, and AA and nucleotide sugar metabolism.

\section{DISCUSSION}

Circadian rhythms occur in almost all organisms and regulate a series of metabolic and physiologic functions. Peek et al. (2012) have shown that core elements of the biological clock are closely related to the regulation of mammalian energy metabolism, and these elements may interact and restrict each other, which creates a certain rhythm in energy variations. Milk is a complex and complete food that contains the essential nutrients for young mammals. A previous study reported that higher levels of dairy consumption are associated with a lower risk of mortality and cardiovascular disease (Dehghan et al., 2018). In the present study, we evaluated the milk composition, antioxidant parameters, hormone levels, immune indices, metabolomics, and lipidomics to explore the differences between day milk and night milk.

Malondialdehyde is a marker of oxidative stress, which can indicate a counter-balance to high states of oxidative phosphorylation. Results from previous research indicated that antioxidant enzymes have a circadian rhythm, which can reflect physiological response to oxidative stress in living things (Krishnan et al., 2008). In our study, the average MDA level in night milk was significantly reduced, indicating that metabolic state of mammary gland by time of day.

Some findings suggest that night milk could improve sleep quality because of its high concentrations of MLT (Cohen Engler et al., 2012). As a naturally occurring hormone, MLT is synthesized at high levels and regulates sleep during the night (Milagres et al., 2014). The secretion of MLT shows a circadian pattern. Castro et al. (2011) calculated the contents of MLT in milk using the area under the curve (AUC) from 0700 to 2200 $\mathrm{h}$ and 2300 to $0600 \mathrm{~h}$ and found that AUC per hour $(0700-2200 \mathrm{~h})$ was $0.4 \pm 0.2 \mathrm{pg} / \mathrm{mL}$ and $(2300-0600$ h) $2.2 \pm 0.5 \mathrm{pg} / \mathrm{mL}$. This diurnal pattern has also been reported in human milk (Illnerová et al., 1993). The findings of this study are consistent with previous studies showing differences in MLT between day and night. Thus, the results of this study found more MLT in night milk primarily associated with differences in the timing of elevated concentrations of MLT.

Heat shock proteins (HSP) comprise a group of stress indicators that signal when the body is subjected to elevated temperatures, oxidative stress, and other stressful situations (Zuo et al., 2016). The HSP play a key role in maintaining homeostasis and can protect 




CL


MGDG

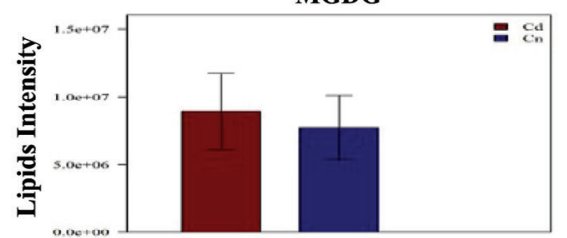

PC

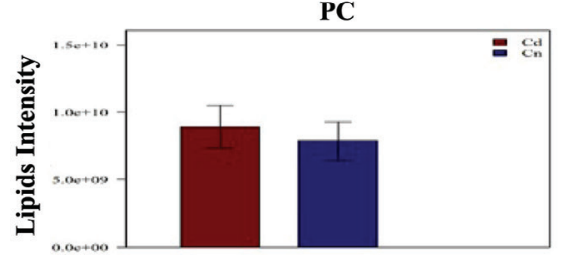

phSM

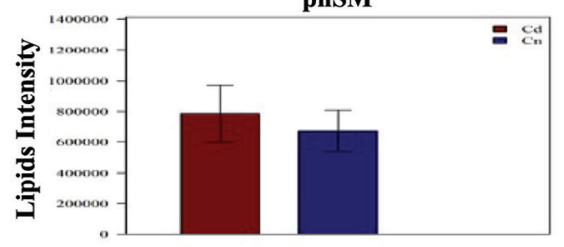

SM

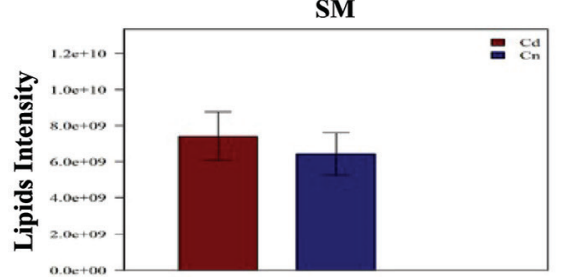

CerG1

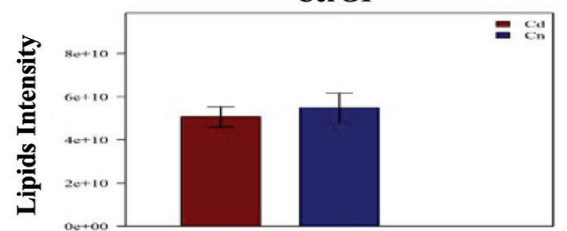

DG

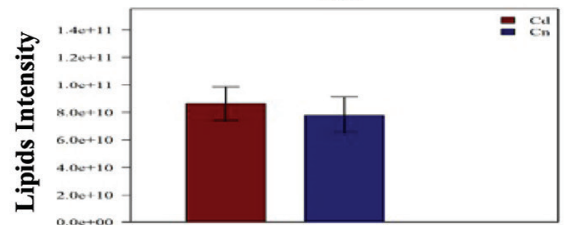

LPI

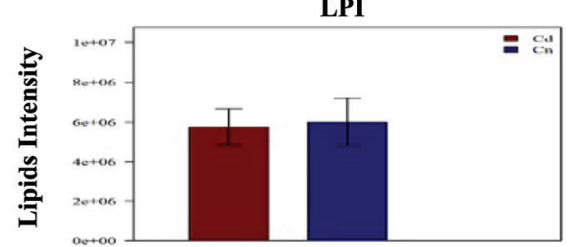

OAHFA

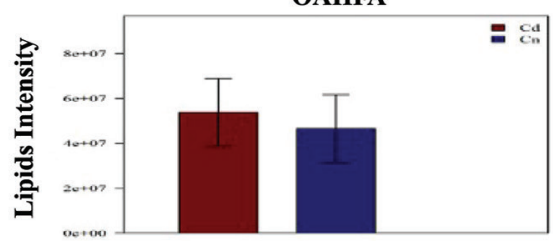

PE

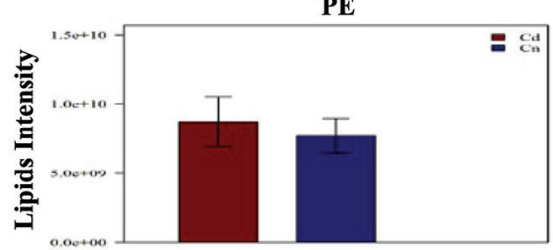

PI

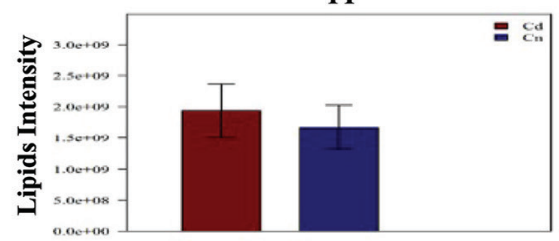

So

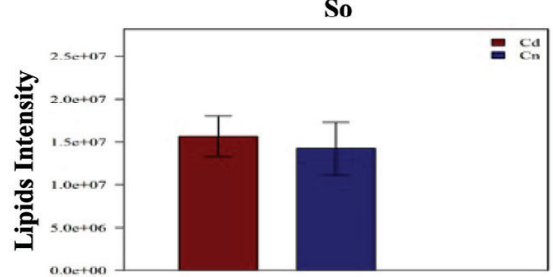

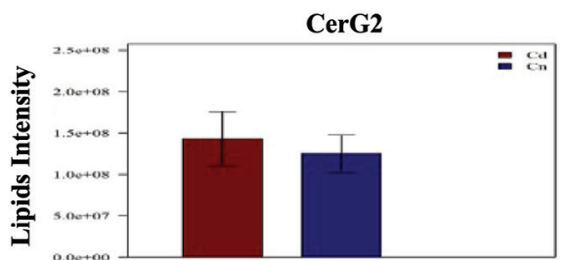

LPC

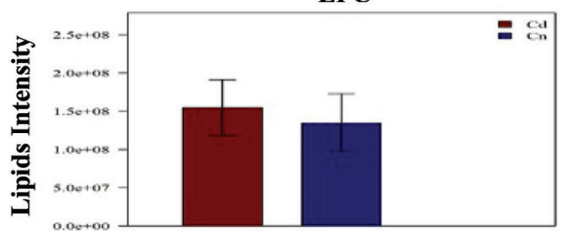

MG

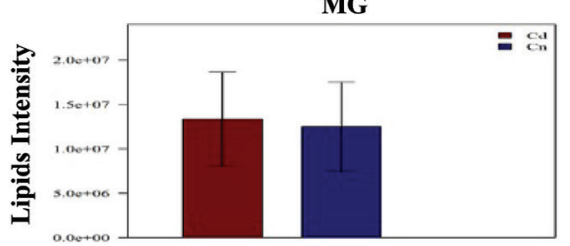

PA

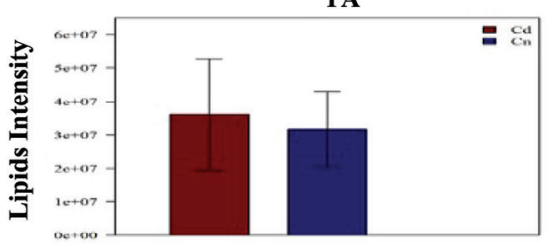

PG

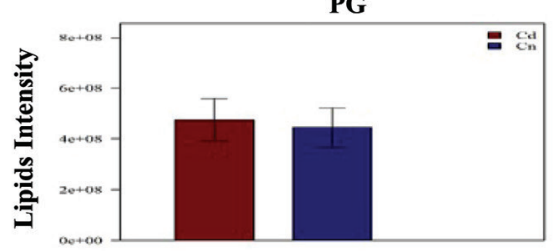

PS

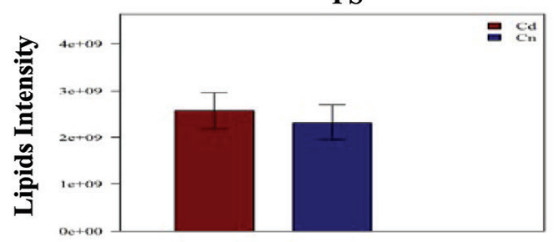

TG



Figure 3. Composition analysis of lipid classes between day milk and night milk. Red histogram represents day milk, and blue histogram represents night milk. Cer $=$ ceramide; CerG1 $=$ simple glc series; CerG2 $=$ simple glc series; CL $=$ cardiolipins; DG $=$ diacylglycerol; $\mathrm{LPC}=$ lyso-pc; LPE = lyso-pe; LPI = lyso-pi; MG = monogalactosyl; MGDG = monogalactosyl diacylglycerols; OAHFA = O-acyl- $\omega$-hydroxy fatty acid; PA = phosphatidic acids; $\mathrm{PC}=$ phosphatidylcholine; $\mathrm{PE}=$ phosphatidylethanolamine; $\mathrm{PG}=$ phosphatidylglycerols; phSM $=$ phytosphingosine; PI = phosphatidylinositol; $\mathrm{PS}$ = phosphatidylserine; $\mathrm{SM}=$ sphingomyelin; So = sphingosine; $\mathrm{TG}=$ triglyceride. 
Teng et al.: ARE DAY MILK AND NIGHT MILK THE SAME?

Table 5. Lipid metabolites showing significant differences between day milk and night milk $(\mathrm{n}=10)$

\begin{tabular}{|c|c|c|c|c|c|c|c|}
\hline Lipid ion & Class & Ion formula & CalMz $^{1}$ & $\mathrm{RT}^{2}(\min )$ & $\mathrm{VIP}^{3}$ & $\mathrm{FC}^{4}$ & $P$-value \\
\hline $\mathrm{TG}^{5}(16: 0 / 14: 0 / 18: 2)+\mathrm{NH}_{4}$ & TG & C51 H98 O6 N1 & 820.74 & 22.95 & 0.58 & 2.54 & 0.019 \\
\hline TG $(19: 1 / 18: 1 / 18: 2)+\mathrm{NH}_{4}$ & TG & C58 H108 O6 N1 & 914.82 & 23.30 & 0.54 & 1.62 & 0.023 \\
\hline TG $(18: 1 / 18: 1 / 22: 4)+\mathrm{NH}_{4}$ & TG & C61 H110 O6 N1 & 952.83 & 23.20 & 0.70 & 1.51 & 0.030 \\
\hline
\end{tabular}

${ }^{1} \mathrm{CalMz}=$ mass-to-charge ratio.

${ }^{2} \mathrm{RT}=$ retention time.

${ }^{3} \mathrm{VIP}=$ variable influence on projection.

${ }^{4} \mathrm{FC}=$ fold change, mean value of peak area obtained from day milk group/mean value of peak area obtained from night milk group. If the FC value more than 1 , it means that metabolites are more in day milk than in night milk.

${ }^{5} \mathrm{TG}=$ triglyceride.

against cellular stress (Baykalir et al., 2020). Reiter et al. (2016) reported that MLT exerts strong antioxidant effects on the cell membrane, cytoplasm, or nucleus by scavenging several oxidation products, free radicals, and reactive oxygen species. A previous study in chickens reported that the intermittent lighting photoperiods (2000-0300 h) increased MLT concentration and significantly reduced the concentration of serum HSP70, compared with continuous lighting (Zhao et al., 2019). Thus, photoperiod had an important effect on MLT and HSP70 concentrations. In our study, the levels of
HSP70 and HSP90 in night milk were reduced, which might be related to the higher concentration of MLT in night milk and the circadian rhythm observed in the levels of HSP.

The IFN- $\gamma$ cytokine is produced by activated $\mathrm{T}$ cells and natural killer cells. Liu et al. (2006) reported that the PER2 circadian clock gene is a key regulator of natural killer cell function, which provides a direct link between mammalian circadian rhythms and immune parameters. Those researchers reported a significant decline in the levels of IFN- $\gamma$ in the serum of $\mathrm{Per2}^{-/-}$
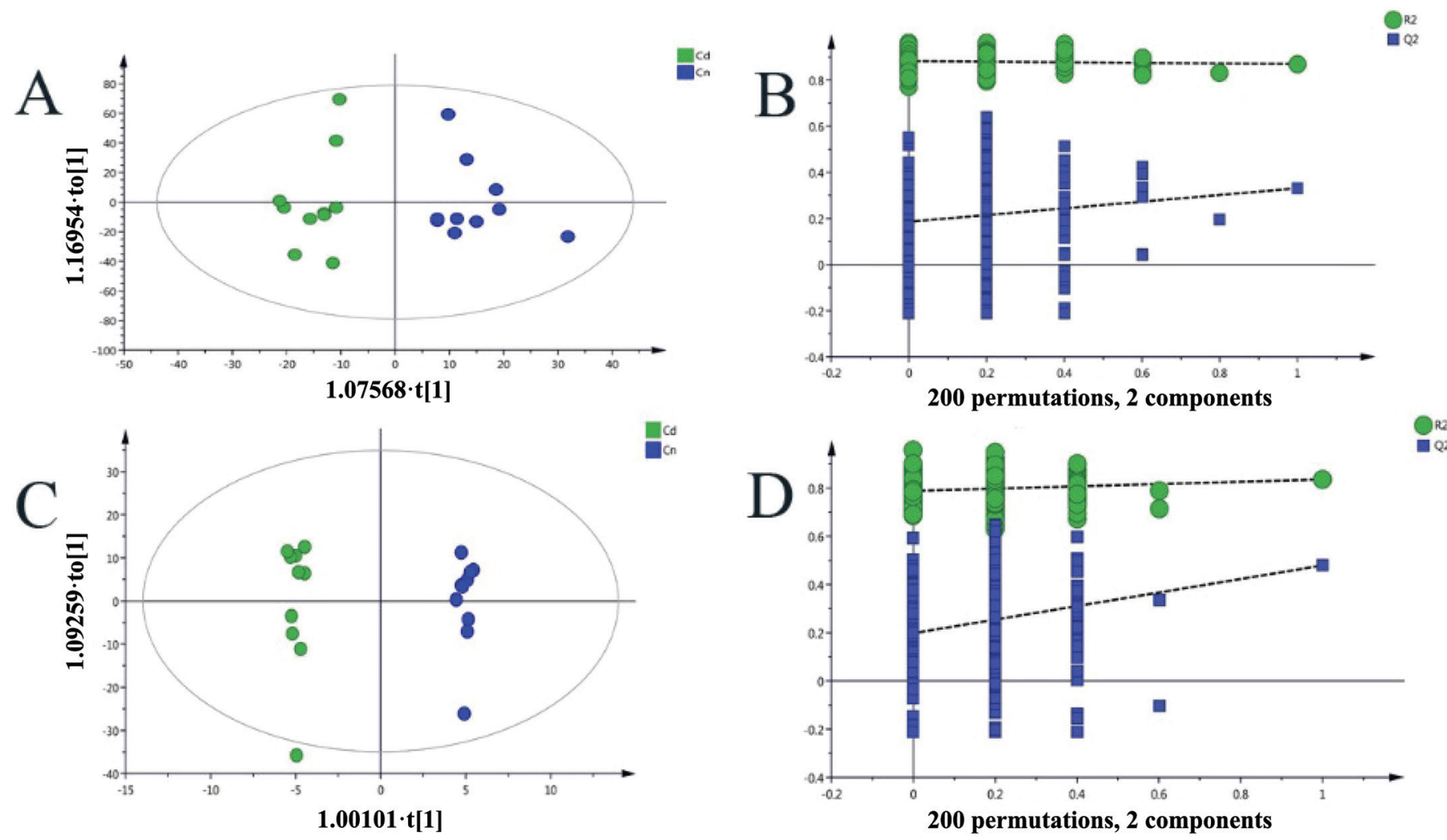

Figure 4. Orthogonal partial least squares discriminant analysis (OPLS-DA) score plots (A, C) and corresponding validation plots of partial least squares discriminant analysis (PLS-DA) (B, D) in positive/negative mode. Green points represent day milk, and blue points represent night milk. $\mathrm{Cd}=$ day milk, $\mathrm{Cn}=$ night milk. 

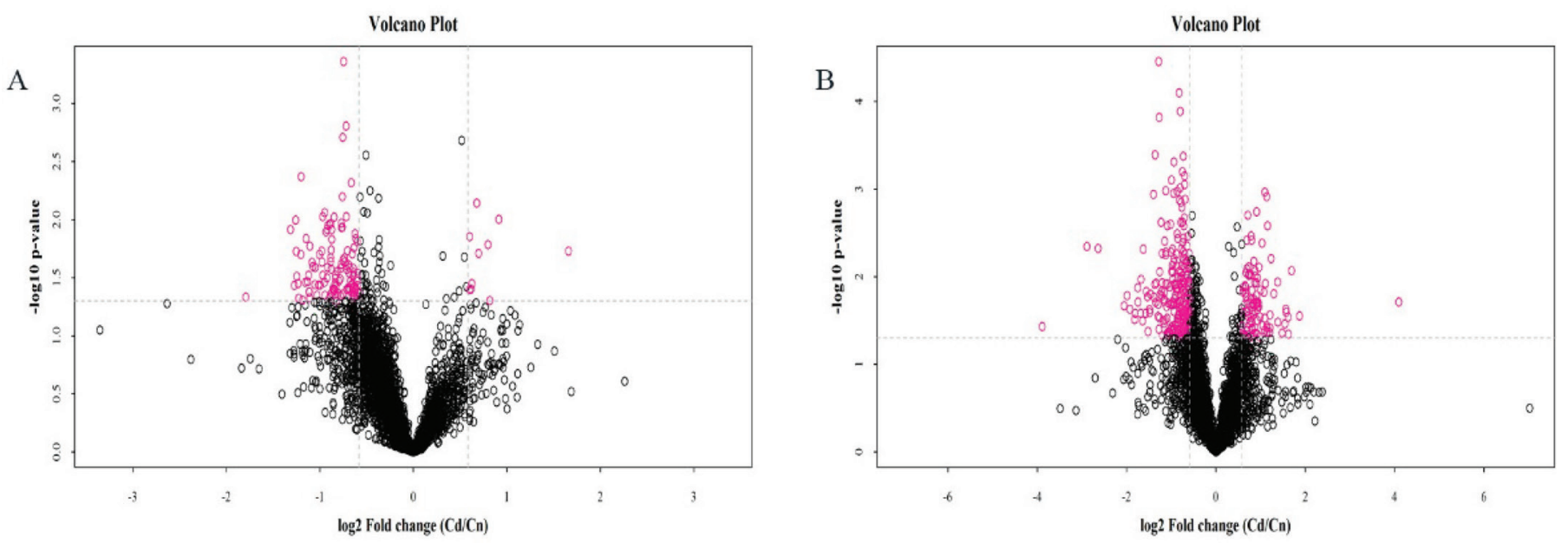

Figure 5. Volcano plot of metabolomics showing the positive $(\mathrm{A})$ and negative $(\mathrm{B})$ ion modes $(\mathrm{n}=10)$. Red points represent significantly different metabolites based on the results of fold change (FC) analysis and the $t$-test in positive and negative modes $(\mathrm{FC}>1.5$ and $P<0.05$ ). $\mathrm{FC}=$ fold change, mean value of peak area obtained from day milk group/mean value of peak area obtained from night milk group. Cd $=$ day milk; $\mathrm{Cn}=$ night milk.

mice following lipopolysaccharide challenge (Liu et al., 2006). Colombo et al. (1992) reported that MLT increases IFN- $\gamma$ production in murine splenocytes. In the present study, our data showed that the concentration of IFN- $\gamma$ in night milk was higher than that of day milk. This could be attributed to the high levels of MLT in night milk and the circadian rhythm observed in IFN- $\gamma$ levels, which are lower during the day and higher at night (Wichmann et al., 1996).

Milk fat is an important source of essential fatty acids, and it can also act as a carrier for the fat-soluble vitamins A, D, and E (Kanwar et al., 2009). Lipidomics is an ideal method to quantitatively analyze all lipids in biological samples, and can systematically analyze changes in lipid composition and expression (Schroeder and Brunet, 2015). In the present study, a total of 21 lipid classes and 1,094 lipid species, which contained 379 TG, were detected in the milk samples. The majority of the lipid species were TG (33\%). The TG account for about $95 \%$ of total milk fat and can be found in varying concentrations, which can be affected a several factors, such as nutrition, the environment, and physiological status. A previous study suggested that the levels of lipid species in blood are generally higher during the light phase (mid-morning to noon) and exhibit circadian oscillations (Dallmann et al., 2012). Similarly, lipidomics analysis on human blood plasma revealed that $13 \%$ of lipid species exhibit circadian oscillations, and TG achieve peak levels after $8 \mathrm{~h}$ of light (Chua et al., 2013). In the present study, a total of 1,094 lipid species were detected; 379 were TG, which represented the highest among all lipid species. Our findings that TG accumulate in milk during the day, as they do in blood plasma, and are apparently influenced by the circadian oscillations, are consistent with the findings of previous studies. Further studies should be focused on identifying the molecular mechanisms that drive the circadian accumulation of TG in the milk of dairy cows.

Metabolomics is an effective method to study the metabolites in fluids or tissues, understand physiological and biochemical status, and facilitate further interpretation of the associated biological principles (Zhao et al., 2014). Metabolite profiling studies add greater complexity within the context of circadian clock-controlled metabolic functions. Various studies have shown that many metabolites, such as AA, carbohydrates, and lipids, as well as nucleotide pathways, show oscillations in the liver (Eckel-Mahan et al., 2012), muscle (Dyar et al., 2014), and plasma (Ribas-Latre et al., 2015). In the current study, we identified 36 differential compounds between day milk and night milk using LC-MS analysis. In day milk, N-acetyl-D-glucosamine, cis-aconitate, and D-sorbitol were found at higher concentrations than they were in night milk. The FC of these 3 metabolites were $1.479,2.195$, and 3.070, respectively. Compared with day milk, the levels of 33 metabolites in night milk, including carbohydrates, lipids, AA, and aromatic compounds were increased. This indicates that there are differences in AA metabolism, carbohydrate metabolism, and lipid metabolism between night milk and day milk.

In terms of carbohydrate metabolism, compared with day milk, the levels of D-lactose, alpha-D-glucose, and D-glucose-6-phosphate in night milk were higher. Previous studies have demonstrated that blood glucose and milk synthesis exhibit a circadian rhythm in dairy 
cows (Salfer et al., 2016). As the nutrients in milk are transported from the blood, variations in the blood also affect the composition of the milk. Consistent with this observation, our data indicated that there are differences in the levels of D-glucose between day milk and night milk. Glucose is the major precursor of lactose synthesis, which can be used to synthesize lactose (Cant et al., 2002). In the lactose synthesis process of the mammary epithelial cell, glucose-6-phosphate is produced when glucose is irreversibly phosphorylated and then converted to uridine diphosphate-galactose in the cytoplasm, and then both glucose and uridine diphosphate-galactose finally are used to synthesize lactose in the Golgi membrane (Zhao, 2014). In this study, the increasing of D-glucose and glucose-6-phosphate may lead to the D-lactose increasing in the night milk.

In terms of lipid metabolism, the absorption of lipids also showed a circadian rhythm (Pan and Hussain,
2009). Cholic acid is a metabolite of cholesterol, which reaches its peak in the dark phase and begins to decrease in the light phase (Duez et al., 2008). Our data suggest that higher concentrations of stearidonic acid, eicosapentaenoic acid, myristoleic acid, cis-9-palmitoleic acid, cholic acid, and creatine were observed in night milk compared with day milk. These results of this experiment are in accordance with the previous research. The levels of fatty acids in milk are affected by the levels of short-chain VFA in the rumen (Bernard et al., 2008). The gut microbiota and its metabolites reportedly exhibit circadian rhythms. The VFA of metabolites could affect the expression of the circadian clock and VFArelated transporter genes (Matenchuk et al., 2020; Yin et al., 2020), which suggests a difference in the levels of fatty acids between day milk and night milk.

Cow's milk contains several branched-chain AA, which are important for protein quality (Willett and

Table 6. Identification of significantly different metabolites between day milk and night milk $(\mathrm{n}=10)$



${ }^{1} \mathrm{VIP}=$ variable influence on projection.

${ }^{2} \mathrm{FC}=$ fold change, mean value of peak area obtained from day milk group/mean value of peak area obtained from night milk group. If the FC value more than 1 , it means that metabolites are more in day milk than in night milk.

${ }^{3} \mathrm{RT}=$ retention time. 


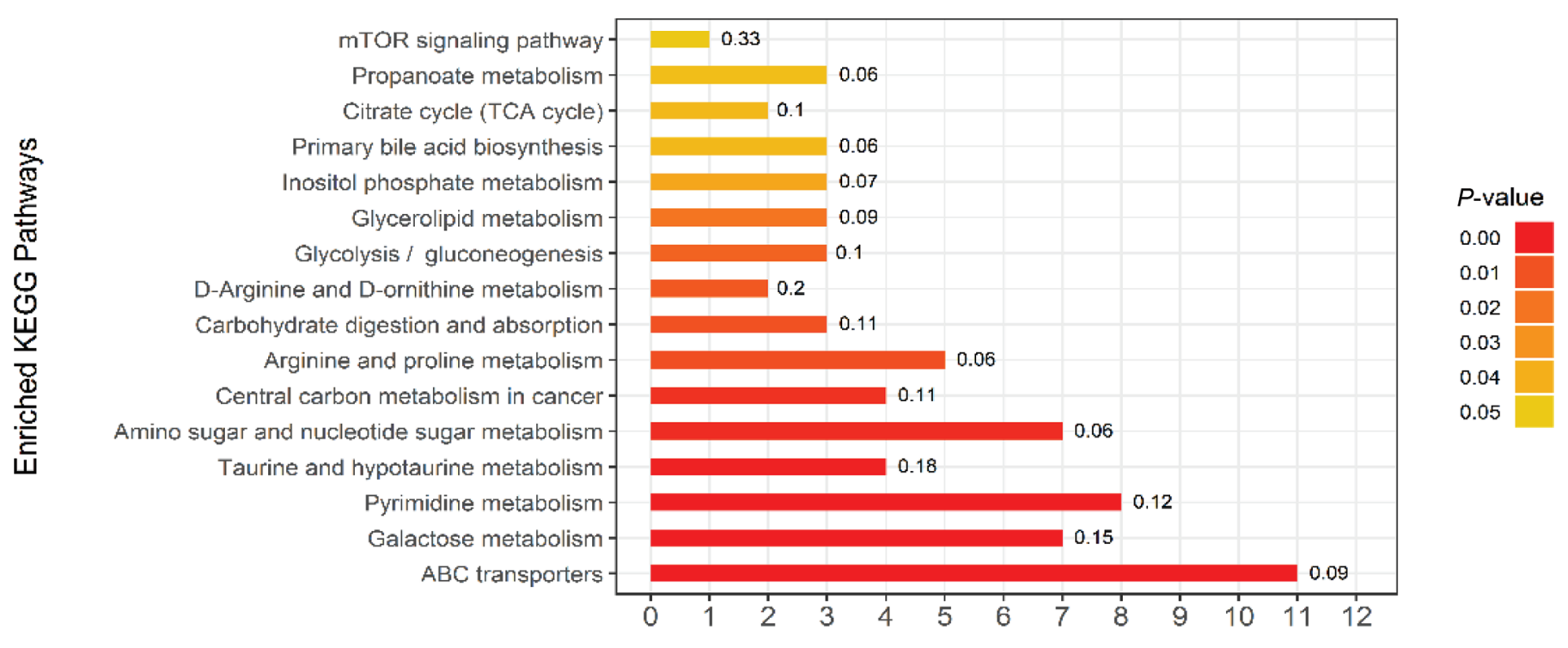

Compound number

Figure 6. Key metabolic pathways that differ between day milk and night milk $(\mathrm{n}=10)$. This figure aims to find pathways significantly changed based on enrichment and topology analysis. The x-axis represents compound numbers, and the y-axis represents enriched Kyoto Encyclopedia of Genes and Genomes (KEGG) pathways. The colors represent pathway impact values. The numbers to the right of the bars in the graph mean the proportion of differential metabolites in the total number of metabolites in this pathway. mTOR $=$ mammalian target of rapamycin; TCA $=$ tricarboxylic acid.

Ludwig, 2020). The AA in blood are relatively stable, but they also show biological rhythm changes. The majority of plasma AA increased in the evening (Riggio et al., 1989). The biological rhythm time can be estimated by measuring the blood AA level (Kasukawa et al., 2012). Compared with day milk, night milk contains higher levels of essential and nonessential AA required in humans, including N6-methyl-L-lysine, L-alanine, taurine, and D-proline. The results of this experiment are compatible with the above results, which indicate a difference in the composition of AA between day milk and night milk.

Changes in the circadian rhythm also affect physiological changes in energy (Peek et al., 2012). The most enriched pathway in our study was the mTOR signaling pathway, which was mainly associated with changes in AMP between day milk and night milk. The mTOR signaling pathway plays an important role in regulating the cell cycle, protein synthesis, and energy metabolism (Martin and Hall, 2005). The AMP-activated protein kinase (AMPK) enzyme is a key factor in the regulation of energy metabolism in cells. The AMPK enzyme is activated by an increased AMP:ATP ratio (Hardie, 2007). Recent studies have shown that cellular energy status is transmitted to TSC2 via AMPK, which can inhibit RHEB and ultimately mTOR activity (Hardie, 2004). The mTOR signaling pathway, the most en- riched pathway between night milk and day milk, was related to circadian metabolism. Indeed, as mentioned before, the amplitude of metabolite oscillations is often relatively limited. However, the details of the associated underlying mechanisms need further research.

\section{CONCLUSIONS}

These results suggest that night milk contains reduced levels of MDA proinflammatory factors and increased levels of MLT and IFN- $\gamma$ inflammatory inhibitory factors. Significant differences were noted between day milk and night milk based on the results of metabolomics and lipidomics. Thirty-nine differential metabolites were found between day milk and night milk. Night milk had greater proportions of beneficial unsaturated fatty acids and AA. The underlying causes of these findings is associated with alterations in the metabolic status in response to the circadian rhythm.

\section{ACKNOWLEDGMENTS}

This work was supported by the China Agriculture (Dairy) Research System (Beijing, China; CARS-36). The authors thank Hongrui Zhang and Shikun Wang of Henan Agricultural University (Zhengzhou, China) for their assistance in feeding and caring for the animals as 
well as sample collection. The authors declare that the research was conducted in the absence of any commercial or financial relationships that could be construed as a potential conflict of interest. The data used to support the findings of this study are available from the corresponding author upon request. L. F. Wang and T. Y. Gao conceived and designed the experiments. Z. W. Teng, L. Q. Han, and L. Y. Zhang performed the experiments and wrote the paper. G. Q. Yang and H. X. Lian analyzed the data. T. Fu, and Y. Sun contributed reagents, materials, and analysis tools.

\section{REFERENCES}

Alila-Johansson, A., L. Eriksson, T. Soveri, and M. L. Laakso. 2004. Daily and annual variations of free fatty acid, glycerol and leptin plasma concentrations in goats (Capra hircus) under different photoperiods. Comp. Biochem. Physiol. A Mol. Integr. Physiol. 138:119-131. https://doi.org/10.1016/j.cbpb.2004.02.021.

Asher, A., A. Shabtay, A. Brosh, H. Eitam, R. Agmon, M. CohenZinder, A. E. Zubidat, and A. Haim. 2015. "Chrono-functional milk": The difference between melatonin concentrations in nightmilk versus day-milk under different night illumination conditions. Chronobiol. Int. 32:1409-1416. https://doi.org/10.3109/07420528 .2015.1102149.

Asher, G., and P. Sassone-Corsi. 2015. Time for food: The intimate interplay between nutrition, metabolism, and the circadian clock. Cell 161:84-92. https://doi.org/10.1016/j.cell.2015.03.015.

Baykalir, Y., U. G. Simsek, M. Erisir, O. Otlu, G. Gungoren, A. Gungoren, and S. Aslan. 2020. Photoperiod effects on carcass traits, meat quality, and stress response in heart and lung of broilers. S. Afr. J. Anim. Sci. 50:138-149. https://doi.org/10.4314/sajas.v50i1 .15 .

Bernard, L., C. Leroux, and Y. Chilliard. 2008. Expression and nutritional regulation of lipogenic genes in the ruminant lactating mammary gland. Adv. Exp. Med. Biol. 606:67-108. https://doi .org/10.1007/978-0-387-74087-4_2.

Cant, J. P., D. R. Trout, F. Qiao, and N. G. Purdie. 2002. Milk synthetic response of the bovine mammary gland to an increase in the local concentration of arterial glucose. J. Dairy Sci. 85:494-503. https://doi.org/10.3168/jds.S0022-0302(02)74100-3.

Castro, N., M. Spengler, V. Lollivier, O. Wellnitz, H. H. D. Meyer, and R. M. Bruckmaier. 2011. Diurnal pattern of melatonin in blood and milk of dairy Cows. Milchwissenschaft 66:352-353.

Chua, E. C., G. Shui, I. T. Lee, P. Lau, L. C. Tan, S. C. Yeo, B. D. Lam, S. Bulchand, S. A. Summers, K. Puvanendran, S. G. Rozen, M. R. Wenk, and J. J. Gooley. 2013. Extensive diversity in circadian regulation of plasma lipids and evidence for different circadian metabolic phenotypes in humans. Proc. Natl. Acad. Sci. USA 110:14468-14473. https://doi.org/10.1073/pnas.1222647110.

Cohen Engler, A., A. Hadash, N. Shehadeh, and G. Pillar. 2012. Breastfeeding may improve nocturnal sleep and reduce infantile colic: Potential role of breast milk melatonin. Eur. J. Pediatr. 171:729-732. https://doi.org/10.1007/s00431-011-1659-3.

Colombo, L. L., G. J. Chen, M. C. Lopez, and R. R. Watson. 1992. Melatonin induced increase in gamma-interferon production by murine splenocytes. Immunol. Lett. 33:123-126. https://doi.org/ 10.1016/0165-2478(92)90035-M.

Dallmann, R., A. U. Viola, L. Tarokh, C. Cajochen, and S. A. Brown. 2012. The human circadian metabolome. Proc. Natl. Acad. Sci. USA 109:2625-2629. https://doi.org/10.1073/pnas.1114410109.

Davies, S. K., J. E. Ang, V. L. Revell, B. Holmes, A. Mann, F. P. Robertson, N. Cui, B. Middleton, K. Ackermann, M. Kayser, A. E. Thumser, F. I. Raynaud, and D. J. Skene. 2014. Effect of sleep deprivation on the human metabolome. Proc. Natl. Acad. Sci. USA 111:10761-10766. https://doi.org/10.1073/pnas.1402663111.
Dehghan, M., A. Mente, S. Rangarajan, P. Sheridan, V. Mohan, R. Iqbal, R. Gupta, S. Lear, E. Wentzel-Viljoen, A. Avezum, P. Lopez-Jaramillo, P. Mony, R. P. Varma, R. Kumar, J. Chifamba, K. F. Alhabib, N. Mohammadifard, A. Oguz, F. Lanas, D. Rozanska, K. B. Bostrom, K. Yusoff, L. P. Tsolkile, A. Dans, A. Yusufali, A. Orlandini, P. Poirier, R. Khatib, B. Hu, L. Wei, L. Yin, A. Deeraili, K. Yeates, R. Yusuf, N. Ismail, D. Mozaffarian, K. Teo, S. S. Anand, and S. Yusuf. 2018. Association of dairy intake with cardiovascular disease and mortality in 21 countries from five continents (PURE): A prospective cohort study. Lancet 392:2288-2297. https://doi.org/10.1016/S0140-6736(18)31812-9.

Duez, H., J. N. van der Veen, C. Duhem, B. Pourcet, T. Touvier, C. Fontaine, B. Derudas, E. Bauge, R. Havinga, V. W. Bloks, H. Wolters, F. H. van der Sluijs, B. Vennstrom, F. Kuipers, and B. Staels. 2008. Regulation of bile acid synthesis by the nuclear receptor Rev-erbalpha. Gastroenterology 135:689-698.e5. https:// doi.org/10.1053/j.gastro.2008.05.035.

Dyar, K. A., S. Ciciliot, L. E. Wright, R. S. Bienso, G. M. Tagliazucchi, V. R. Patel, M. Forcato, M. I. Paz, A. Gudiksen, F. Solagna, M. Albiero, I. Moretti, K. L. Eckel-Mahan, P. Baldi, P. SassoneCorsi, R. Rizzuto, S. Bicciato, H. Pilegaard, B. Blaauw, and S. Schiaffino. 2014. Muscle insulin sensitivity and glucose metabolism are controlled by the intrinsic muscle clock. Mol. Metab. 3:29-41. https://doi.org/10.1016/j.molmet.2013.10.005.

Eckel-Mahan, K. L., V. R. Patel, R. P. Mohney, K. S. Vignola, P. Baldi, and P. Sassone-Corsi. 2012. Coordination of the transcriptome and metabolome by the circadian clock. Proc. Natl. Acad. Sci USA 109:5541-5546. https://doi.org/10.1073/pnas.1118726109.

Hardie, D. G. 2004. The AMP-activated protein kinase pathway-new players upstream and downstream. J. Cell Sci. 117:5479-5487. https://doi.org/10.1242/jcs.01540.

Hardie, D. G. 2007. AMP-activated/SNF1 protein kinases: Conserved guardians of cellular energy. Nat. Rev. Mol. Cell Biol. 8:774-785. https://doi.org/10.1038/nrm2249.

Illnerová, H., M. Buresova, and J. Presl. 1993. Melatonin rhythm in human milk. J. Clin. Endocrinol. Metab. 77:838-841. https://doi .org/10.1210/jcem.77.3.8370707.

Kanwar, J. R., R. K. Kanwar, X. Sun, V. Punj, H. Matta, S. M. Morley, A. Parratt, M. Puri, and R. Sehgal. 2009. Molecular and biotechnological advances in milk proteins in relation to human health. Curr. Protein Pept. Sci. 10:308-338. https://doi.org/10 $.2174 / 138920309788922234$

Kasukawa, T., M. Sugimoto, A. Hida, Y. Minami, M. Mori, S. Honma, K. Honma, K. Mishima, T. Soga, and H. R. Ueda. 2012. Human blood metabolite timetable indicates internal body time. Proc. Natl. Acad. Sci. USA 109:15036-15041. https://doi.org/10.1073/ pnas. 1207768109 .

Krishnan, N., A. J. Davis, and J. M. Giebultowicz. 2008. Circadian regulation of response to oxidative stress in Drosophila melanogaster. Biochem. Biophys. Res. Commun. 374:299-303. https://doi .org/10.1016/j.bbrc.2008.07.011.

Kumar Jha, P., E. Challet, and A. Kalsbeek. 2015. Circadian rhythms in glucose and lipid metabolism in nocturnal and diurnal mammals. Mol. Cell. Endocrinol. 418:74-88. https://doi.org/10.1016/j mce.2015.01.024.

Liu, J., G. Mankani, X. Shi, M. Meyer, S. Cunningham-Runddles, X. Ma, and Z. S. Sun. 2006. The circadian clock Period 2 gene regulates gamma interferon production of NK cells in host response to lipopolysaccharide-induced endotoxic shock. Infect. Immun. 74:4750-4756. https://doi.org/10.1128/IAI.00287-06.

Martin, D. E., and M. N. Hall . 2005. The expanding TOR signaling network. Curr. Opin. Cell Biol. 17:158-166. https://doi.org/10 $.1016 /$ j.ceb.2005.02.008.

Matenchuk, B. A., P. J. Mandhane, and A. L. Kozyrskyj. 2020. Sleep, circadian rhythm, and gut microbiota. Sleep Med. Rev. 53:101340. https://doi.org/10.1016/j.smrv.2020.101340.

Milagres, M. P., V. P. Minim, L. A. Minim, A. A. Simiqueli, L. E. Moraes, and H. S. Martino. 2014. Night milking adds value to cow's milk. J. Sci. Food Agric. 94:1688-1692. https://doi.org/10 $.1002 /$ jsfa. 6480 
Minami, Y., T. Kasukawa, Y. Kakazu, M. Iigo, M. Sugimoto, S. Ikeda, A. Yasui, G. T. van der Horst, T. Soga, and H. R. Ueda. 2009 Measurement of internal body time by blood metabolomics. Proc. Natl. Acad. Sci. USA 106:9890-9895. https://doi.org/10.1073/ pnas.0900617106.

Pan, X., and M. M. Hussain. 2009. Clock is important for food and circadian regulation of macronutrient absorption in mice. J. Lipid Res. 50:1800-1813. https://doi.org/10.1194/jlr.M900085-JLR200.

Peek, C. B., K. M. Ramsey, B. Marcheva, and J. Bass. 2012. Nutrient sensing and the circadian clock. Trends Endocrinol. Metab. 23:312-318. https://doi.org/10.1016/j.tem.2012.02.003.

Piccione, G., G. Caola, and R. Refinetti. 2005. Temporal relationships of 21 physiological variables in horse and sheep. Comp. Biochem. Physiol. A Mol. Integr. Physiol. 142:389-396. https://doi.org/10 $.1016 /$ j.cbpa.2005.07.019.

Reiter, R. J., J. C. Mayo, D. X. Tan, R. M. Sainz, M. AlatorreJimenez, and L. Qin. 2016. Melatonin as an antioxidant: Under promises but over delivers. J. Pineal Res. 61:253-278. https://doi .org/10.1111/jpi.12360.

Ribas-Latre, A., J. M. Del Bas, L. Baselga-Escudero, E. Casanova, A. Arola-Arnal, M. J. Salvado, L. Arola, and C. Blade. 2015. Dietary proanthocyanidins modulate melatonin levels in plasma and the expression pattern of clock genes in the hypothalamus of rats. Mol. Nutr. Food Res. 59:865-878. https://doi.org/10.1002/mnfr 201400571.

Ribas-Latre, A., and K. Eckel-Mahan. 2016. Interdependence of nutrient metabolism and the circadian clock system: Importance for metabolic health. Mol. Metab. 5:133-152. https://doi.org/10 .1016/j.molmet.2015.12.006.

Riggio, O., M. Merli, U. Pièche, A. Romiti, P. Pasqualetti, A. Coppola, D. Danese, P. Cugini, and L. Capocaccia. 1989. Circadian rhythmicity of plasma amino acid variations in healthy subjects. Recenti Prog. Med. 80:591-593.

Romanini, E. B., A. M. Volpato, J. Sifuentes dos Santos, E. H. W. de Santana, C. H. B. de Souza, and A. Ludovico. 2019. Melatonin concentration in cow's milk and sources of its variation. J. Appl. Anim. Res. 47:140-145. https://doi.org/10.1080/09712119.2019 .1583570

Salfer, I., Y. Ying, and K. J. Harvatine. 2016. The timing of feed availability entrains the circadian rhythm of milk synthesis in dairy cattle. J. Anim. Sci. 94(suppl_5):734. https://doi.org/10.2527/ jam2016-1512.

Schroeder, E. A., and A. Brunet. 2015. Lipid profiles and signals for long life. Trends Endocrinol. Metab. 26:589-592. https://doi.org/ 10.1016/j.tem.2015.08.007.
Spicer, R., R. M. Salek, P. Moreno, D. Canueto, and C. Steinbeck. 2017. Navigating freely-available software tools for metabolomics analysis. Metabolomics 13:106. https://doi.org/10.1007/s11306 $-017-1242-7$.

Teng, Z. 2021. Journal of Dairy Science supplemental files .docx. figshare. Journal contribution. https://doi.org/10.6084/m9.figshare .14350580.v1.

Wichmann, M. W., R. Zellweger, C. M. DeMaso, A. Ayala, and I. H. Chaudry. 1996. Melatonin administration attenuates depressed immune functions after trauma-hemorrhage. J. Surg. Res. 63:256262. https://doi.org/10.1006/jsre.1996.0257.

Willett, W. C., and D. S. Ludwig. 2020. Milk and health. N. Engl. J. Med. 382:644-654. https://doi.org/10.1056/NEJMra1903547.

Yin, J., Y. Li, H. Han, J. Ma, G. Liu, X. Wu, X. Huang, R. Fang, K. Baba, P. Bin, G. Zhu, W. Ren, B. Tan, G. Tosini, X. He, T. Li, and Y. Yin. 2020. Administration of exogenous melatonin improves the diurnal rhythms of the gut microbiota in mice fed a high-fat diet. mSystems 5:e00002-e00020. https://doi.org/10.1128/mSystems .00002-20.

Zhao, F. Q. 2014. Biology of glucose transport in the mammary gland. J. Mammary Gland Biol. Neoplasia 19:3-17. https://doi.org/10 .1007/s10911-013-9310-8.

Zhao, R. X., C. H. Cai, P. Wang, L. Zheng, J. S. Wang, K. X. Li, W. Liu, X. Y. Guo, X. A. Zhan, and K. Y. Wang. 2019. Effect of night light regimen on growth performance, antioxidant status and health of broiler chickens from 1 to 21 days of age. AsianAustralas. J. Anim. Sci. 32:904-911. https://doi.org/10.5713/ajas .18 .0525

Zhao, S., J. Zhao, D. Bu, P. Sun, J. Wang, and Z. Dong. 2014. Metabolomics analysis reveals large effect of roughage types on rumen microbial metabolic profile in dairy cows. Lett. Appl. Microbiol. 59:79-85. https://doi.org/10.1111/lam.12247.

Zuo, D., J. Subjeck, and X. Y. Wang. 2016. Unfolding the role of large heat shock proteins: New insights and therapeutic implications. Front. Immunol. 7:75. https://doi.org/10.3389/fimmu.2016.00075.

\section{ORCIDS}

Z. W. Teng (® https://orcid.org/0000-0003-1160-2237

G. Q. Yang (ํ) https://orcid.org/0000-0001-7958-152X

L. F. Wang (ํ) https://orcid.org/0000-0001-6823-8304

Y. Sun $\odot$ https://orcid.org/0000-0002-6170-0831

T. Y. Gao ๑ https://orcid.org/0000-0001-9236-8408 